\title{
Adjustment of Axis Offset Errors during Reaming
}

\section{Andreas Bretz ${ }^{1, a^{*}}$, Felix Geßner ${ }^{1, b}$, Tugrul Öztürk ${ }^{1, c}$, Christian Rinn $^{1, d}$ and Eberhard Abele ${ }^{1, e}$}

${ }^{1}$ Institute of Production Management, Technology and Machine Tools (PTW),

Technische Universität Darmstadt, Otto-Berndt-Straße 2, 64287 Darmstadt

abretz@ptw.tu-darmstadt.de, b gessner@ptw.tu-darmstadt.de, 't.oeztuerk@ptw.tu-darmstadt.de, 'christian.rinn@stud.tu-darmstadt.de, eabele@ptw.tu-darmstadt.de

\section{Keywords: Reaming, Uncertainty, Process Errors}

\begin{abstract}
The reaming process normally takes place at the end of manufacturing processes when a lot of value has already been added. Therefore, reaming plays an important role for the quality of the finished product. To achieve this high quality, the occurring process errors caused by the machine tool and the reamer or incorrect workpiece handling have to be minimised. Measured data of the reaming process allow the prediction of occurring process errors without the need to evaluate the bore with a coordinate measuring machine. However, manufacturing is already completed at this stage and the correction of errors is either no longer possible or very costly. This paper presents an approach to detect axis offsets within the entry phase of the reamer by analysing the process forces. The calculated offset is then compensated by adjusting the nominal value of the motion control.
\end{abstract}

\section{Introduction}

The two-staged process chain solid drilling and reaming is frequently used in the automotive industry. For example, about $42 \%$ of the main process time for manufacturing cylinder heads is used for the process chain drilling and reaming [1]. Due to the fact that the reaming process is carried out at the end of the value chain, any error during reaming can have a negative effect on the final quality of the product [2]. Therefore, reaming process plays a key role in improving the quality of boreholes. Tolerance grades of IT6 or IT7 with an average peak-to-valley height of less than 5 $\mu \mathrm{m}$ can be achieved by reaming [3]. In most cases single-edged reamers are used to achieve smoother surfaces [4]. Those reamers consist of a cutting edge and several guide lines. In comparison, multibladed reamers consist of more than one cutting edge and no guide rails. To guide those reamers circular grinding chamfers are used. Multibladed reamers consist of main and secondary cutting edges, which are arranged on the circumference. This circumstance leads to improved results, due to the simultaneous involvement of all edges during the reaming process [5]. However, any uncertainty during the reaming process can negatively affect the quality of boreholes. Basic types of uncertainty are a) parallel displacement of the tool axis along the boring axis, called axis offset, b) offset of the tool's rotation axes in relation to the motor spindle, called eccentricity error or c) sloped pre-drilled bores due to uneven surfaces, material inclusions, different hardness gradients or other material defects [6], see also Fig. 1.

\section{Detection of Process Errors in Reaming and the Impact on Bore Quality - State of the Art}

To investigate the mentioned types of uncertainty reaming models who provide the possibility of predicting the resulting process forces are presented. For calculation of process forces a mechanistic approach can be deployed in which geometric characteristics of the removed chip are used to calculate the process forces by means of specific cutting force values. In [7] a mechanistic approach that considers axial force and torque is used to determine the cutting forces. However, it does not perform a calculation of resulting radial forces and induced tool deflection. The model presented in [8] enables the examination of lobes that are generated by tool oscillation. Therefore, the resulting 
radial forces and the associated tool deflection are taken into consideration. A detailed view on the effects of disturbances on the geometrical quality of the bore is presented in [9] and [10]. A bore quality error parameter $\delta$ calculated from the generated bore radii is introduced in [10] to specify the effect of disturbances of occurring radial forces. The larger the radial forces the larger the bore quality error parameter.

a) Axis offset

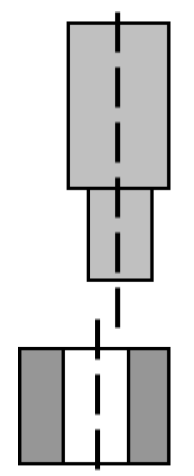

b) Runout error

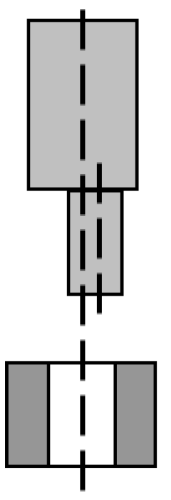

c) Sloped pre-drill bore

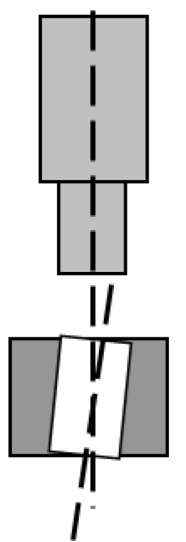

Fig. 1: Different type of process errors in the two staged drilling and reaming process chain

In contrast to the analytical models, an empirical approach was chosen in [11]. A dynamometer was used to measure feed force and torque during reaming. In addition, the vibrations were detected with an accelerometer and the structure-borne noise on the workpiece was recorded with an acoustic emission sensor. The measurements were used to train an artificial neural network to predict surface roughness and runout of the wells. It showed that the combination of the different sensor signals gave better results than the solely observation of feed force and torque.

Previous investigations of the Collaborative Research Centre "CRC 805 - Control of Uncertainty in Load-Carrying Structures in Mechanical Engineering" showed the effects of uncertainty on the process forces and geometrical quality of the bore. The process forces were determined using a multivariable regression model based on experimental data. By taking the chip thickness as an input variable for the regression, the effects of the previously mentioned disturbances can be considered [12]. For example, a misalignment leads to larger stress on one side of the reamer and thus to greater active and passive forces, while lower forces occur on the opposite side. However, Hauer et al. showed in experimental investigations that these process forces do not lead to a deviation of the reaming tool at greater cutting depths due to the support of the reamer over the minor cutting edges [13]. According to [13] the essential area in which an influence of the axis offset has an effect is at the beginning of the reaming process, when the minor cutting edges are not yet supporting the tool (in the following called "entry phase").

Nevertheless, the presented process models can't predict process forces during the beginning of the reaming process. The profile of the pilot bore, the geometry of the cutting edges and the height of the workpiece surface vary in a nano-scale and are different for every workpiece - tool combination. For this reason, the present work introduces an analytical approach to detect and compensate occurring axis offsets during the entry phase (uncertainty type a) in Fig. 1).

\section{Method for the Detection of Axis Offsets}

By a subsequent analysis of the process forces and the comparison with simulation models, the axis offset between the pilot hole and the reamer which occurred during a reaming process can be determined. The mean values of the process forces in $\mathrm{x}$ - and y-direction are approximately zero for a coaxial process, whereas they are unequal zero for a process with axis offset. Fig. 2 shows an example of the measured forces for a process without axis offset (left) and with an axis offset of $90 \mu \mathrm{m}$ in the y-direction (right) during reaming with a multibladed reamer. However, a correction of 
the axis offset after the process is no longer possible because further machining operations would lead to an increase in the desired bore diameter.

In the following, an approach which already determines the axis offset during the entry phase is presented. This offset can then be corrected and the bore completely processed.
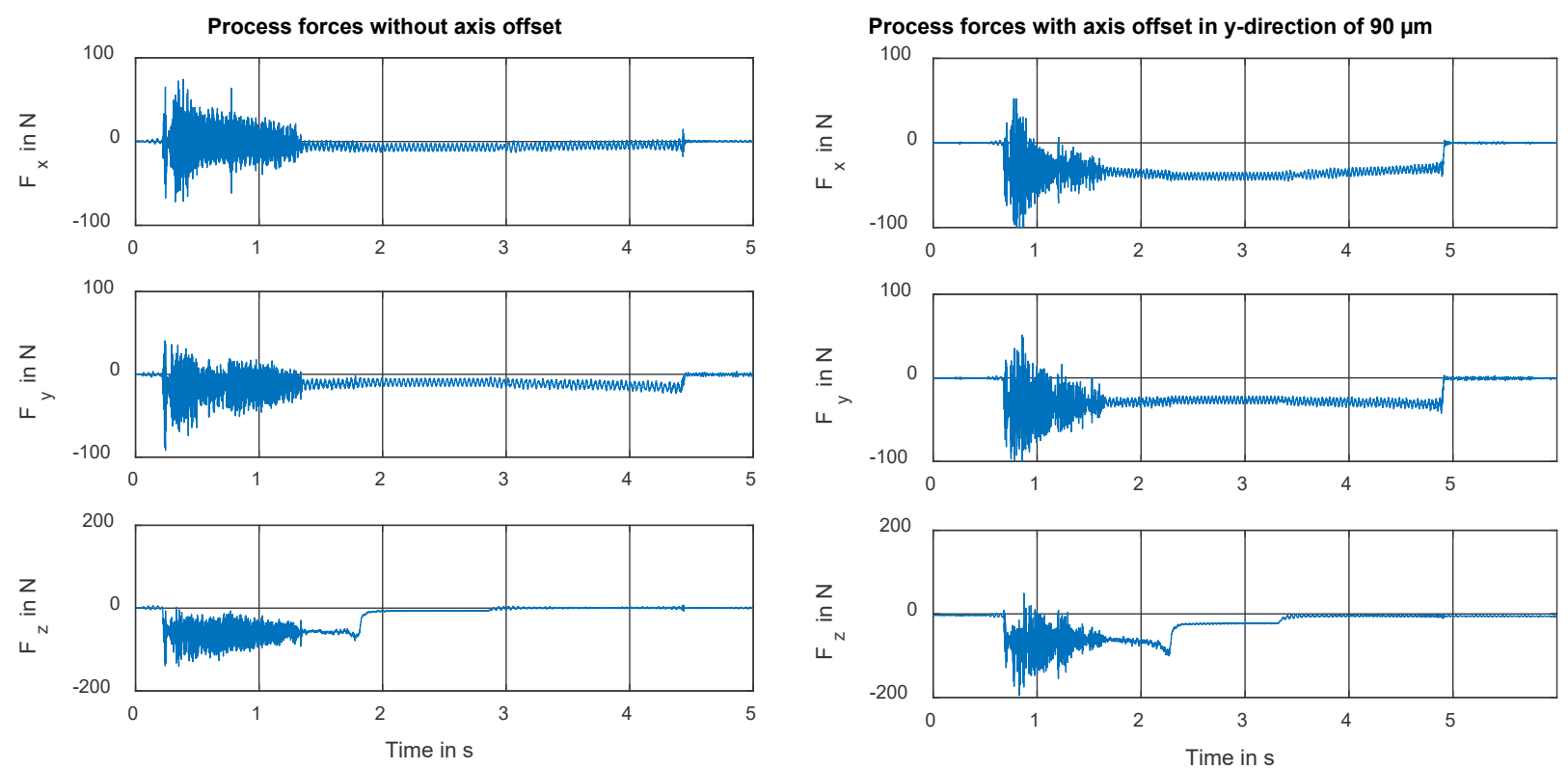

Fig. 2: Comparison of the process forces in the $\mathrm{x}$ and $\mathrm{y}$ directions during reaming without (left) and with (right) axis misalignment

Description of the approach. To determine the existing axis offset, an additional countersinking operation is performed. The phases of the main cutting edges are used to countersink the bore. The bore depth is chosen so that the secondary cutting edges are not yet engaged and sufficient material for correction remains. By measuring the occurring cutting forces by means of a dynamometer, the axis offset is calculated and then corrected.

Fig. 3 shows the pilot hole with diameter $d_{1}$ and the reamer with diameter $d_{2}$ on the left as well as the width of the main cutting edge $w$ and the lead angle $\alpha$. The material allowance on each side in an ideal process with no misalignment is

$$
a_{\mathrm{p}}=\left(d_{2}-d_{1}\right) / 2
$$

and

$$
a_{\mathrm{p}}=\left(d_{2}-d_{1}\right) / 2 \pm x_{\text {offset }}
$$

with axis misalignment $x_{\text {offset }}$. The reamer can move into the bore up to the $\mathrm{z}$ position $z_{1}$ before the main cutting edges touch the workpiece (Fig. 3 (2))

$$
z_{1}=\tan \alpha\left(w-a_{\mathrm{p}}-x_{\text {offset }}\right) .
$$

Up to the depth $z_{2}$, the bore is now countersunk with reduced feed rate so that the secondary cutting edges are not yet engaged and sufficient material for correction remains on each side (Fig. 3 (3)). During this countersinking operation process forces are measured. The reamer is then pulled out. The existing axis offset is calculated using the measured process forces and transferred subsequently to the machine tool control as a correction value. Finally, the bore is reamed with normal process parameters. If there was a misalignment, the countersinking would lead to different material removal on both sides (Fig. 3 (4)). In the direction of misalignment, the bore was countersunk to a depth of $z_{\mathrm{c} 2}$ which is bigger than $z_{\mathrm{c} 1}$ on the opposite side. This leads to the fact, that the reamer touches the workpiece earlier on the side of $z_{\mathrm{c} 1}$ and thus on the opposite side an air cut occurs (Fig. 3 (5)) after correction of the axis offset. As an air cut can lead to a high deflection of the reamer [6], it is also examined whether the deflection of the reamer is bigger by the additional countersinking process compared to a normal reaming process. 


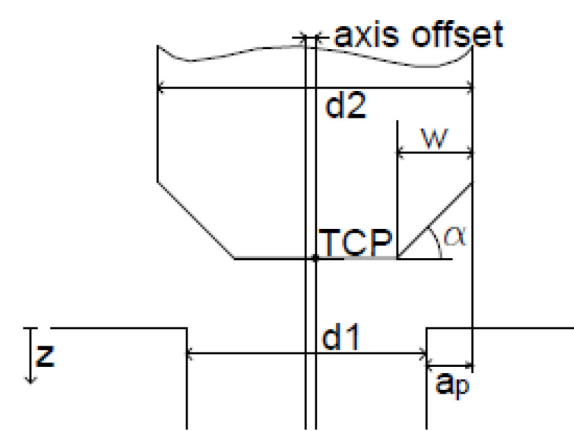

(1)

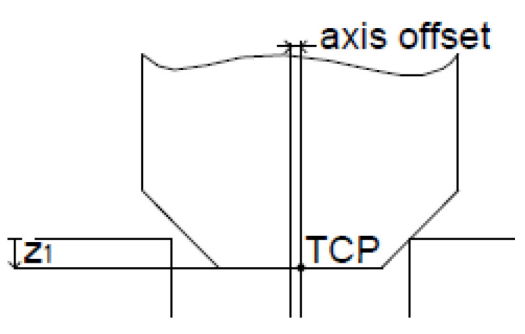

(2)

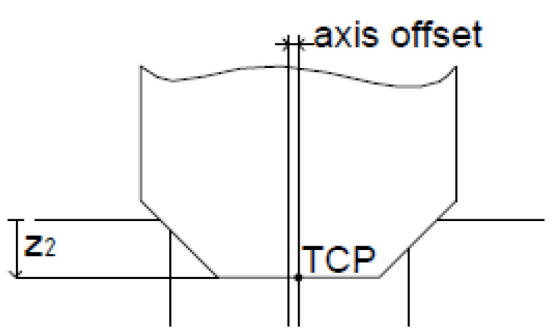

(3)

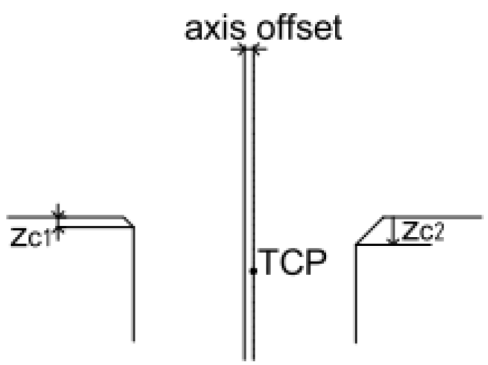

(4)

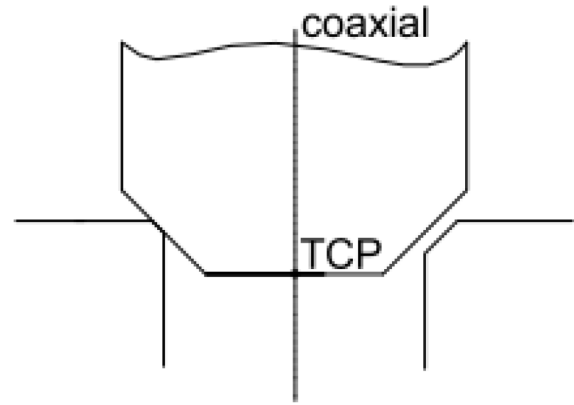

(5)

Fig. 3: Approach of additional countersinking with the reamer

General test conditions. To test the presented approach, cutting tests were carried out. In round blanks with a diameter of $250 \mathrm{~mm}$, pilot holes were drilled with a twisted carbide drills, which were then countersunk and reamed with a multi-bladed reamer. The workpiece materials used were 42CrMo4V and EN-GJL-250.

Table 1: Material properties of the work pieces used

\begin{tabular}{|l|l|l|l|}
\hline & $\boldsymbol{R}_{\mathbf{p}}$ & $\boldsymbol{R}_{\mathbf{m}}$ & Hardness \\
\hline 42CrMo4V & $672 \mathrm{~N} / \mathrm{mm}^{2}$ & $900 \mathrm{~N} / \mathrm{mm}^{2}$ & $280 \mathrm{HV}$ \\
\hline EN-GJL-250 & $200 \mathrm{~N} / \mathrm{mm}^{2}$ & $230 \mathrm{~N} / \mathrm{mm}^{2}$ & $200 \mathrm{HB} 30$ \\
\hline
\end{tabular}

The drill used has a diameter of $d_{1}=13.6 \mathrm{~mm}$ with a $\mathrm{L} / \mathrm{D}$ ratio of 5 . The reamer has a diameter $d_{2}=14 \mathrm{~mm}$ with a L/D ratio of 5.4 and 6 cutting flutes with unequal division. The process parameters used are shown in Table 2.

Table 2: Processing parameters

\begin{tabular}{|l|l|l|l|}
\hline & Feedrate & Lubricant pressure & Cutting speed \\
\hline Drilling & $0.2 \mathrm{~mm} / \mathrm{R}$ & $60 \mathrm{bar}$ & $65 \mathrm{~m} / \mathrm{min}$ \\
\hline Countersinking & $0.1 \mathrm{~mm} / \mathrm{R}$ & \multirow{2}{*}{$40 \mathrm{bar}$} & $75 \mathrm{~m} / \mathrm{min}$ \\
& $0.3 \mathrm{~mm} / \mathrm{R}$ & & $75 \mathrm{~m} / \mathrm{min}$ \\
\hline
\end{tabular}

The depth of cut $a_{\mathrm{p}}$ for the ideal process is $0.2 \mathrm{~mm}$ according to Eq. 1 . The main cutting edges of the reamer have a lead angle of $45^{\circ}$ and a width of $0.5 \mathrm{~mm}$. If there is no misalignment, the position $z_{1}$ at which the cutting edges touch the workpiece is $0.3 \mathrm{~mm}$. The anchoring depth $z_{2}$ was set to $0.43 \mathrm{~mm}$. Thus, a lead angle of $45^{\circ}$ leads to $70 \mu \mathrm{m}$ of remaining material on each side which can then be used to compensate the axis offset.

The machining tests were carried out on a 5-axis machine tool C32 U from Hermle. The blanks were face milled and the pilot holes were drilled. To countersink, the reamer was positioned via the machine control with axis offsets between 0 and $70 \mu \mathrm{m}$ in the $\mathrm{x}$ - and y-direction. After countersinking with a reduced feedrate $\left(f_{l}=0.1 \mathrm{~mm} / \mathrm{R}\right)$, the reamer was pulled out, the offset was corrected and the bore was reamed with a standard feedrate $\left(f_{2}=0.3 \mathrm{~mm} / \mathrm{R}\right)$. With coaxial alignment of reamer and bore, material is removed during countersinking only from depth 
$\mathrm{z}_{1}=0.3 \mathrm{~mm}$ to $\mathrm{z}_{2}=0.43 \mathrm{~mm}$. Due to the reduced feedrate of $0.1 \mathrm{~mm} / \mathrm{R}$, process forces could be measured over more than one full revolution before reaching the depth $\mathrm{z}_{2}$, while at standard feed the distance is covered in less than half a revolution.

The process forces were measured using a stationary 3-axis dynamometer 9255A from Kistler. The measured values were recorded with a sampling rate of $5 \mathrm{kHz}$. The exact shape of the drilled bores were measured on a Leitz PMM 864 coordinate measuring machine with an accuracy of $\pm 1.2 \mu \mathrm{m}$. For this purpose, ten measuring circuits in the reamed area and three in the area of the pilot hole were distributed along the bore depth. In each case, the calculated centre of bore in the xand y-direction, the diameter and the circularity were recorded.

\section{Evaluation of the Experiments}

As a basis for comparison, reference experiments without axis offsets were carried out. The occurring axis offset is only determined by the positioning accuracy of the machine tool, wherein the deviation between drilling position and reaming position is influenced by the tool change and the associated two-time positioning. The deviation can be up to about $13 \mu \mathrm{m}$. Subsequently, tests were carried out with predetermined axis offsets. An overview of the tested combinations is shown in Table 3. Due to the large number of tests required for a full-factorial design, selected offset combinations in the range of $0-70 \mu \mathrm{m}$ with a spacing of $10 \mu \mathrm{m}$ were tested instead.

Table 3: Overview of tested axis offset combinations

\begin{tabular}{|l|l|c|c|c|c|c|c|c|c|c|c|c|c|c|c|c|c|c|c|}
\hline \multirow{2}{*}{ Axis offset } & $\mathrm{x}$ in $\mu \mathrm{m}$ & 0 & 10 & 20 & 30 & 40 & 50 & 60 & 70 & 0 & 0 & 0 & 0 & 20 & 40 & 60 & 10 & 10 & 50 \\
\cline { 2 - 14 } & $\mathrm{y}$ in $\mu \mathrm{m}$ & 0 & 0 & 0 & 0 & 0 & 0 & 0 & 0 & 20 & 30 & 40 & 60 & 20 & 40 & 60 & 30 & 60 & 30 \\
\hline
\end{tabular}

In Fig. 4, two force profiles of the countersinking process for different axis offsets are shown. The left hand side shows a process without axis offsets, whereas an axis offset of $70 \mu \mathrm{m}$ in the $\mathrm{x}$ direction is shown on the right. It can clearly be seen that the process forces without axis offset have lower absolute values and fluctuate less. In addition, an offset in the x-direction can be seen with an axis offset in the $\mathrm{x}$-direction, as was also shown for the actual reaming process in earlier research $[3,5,7]$.
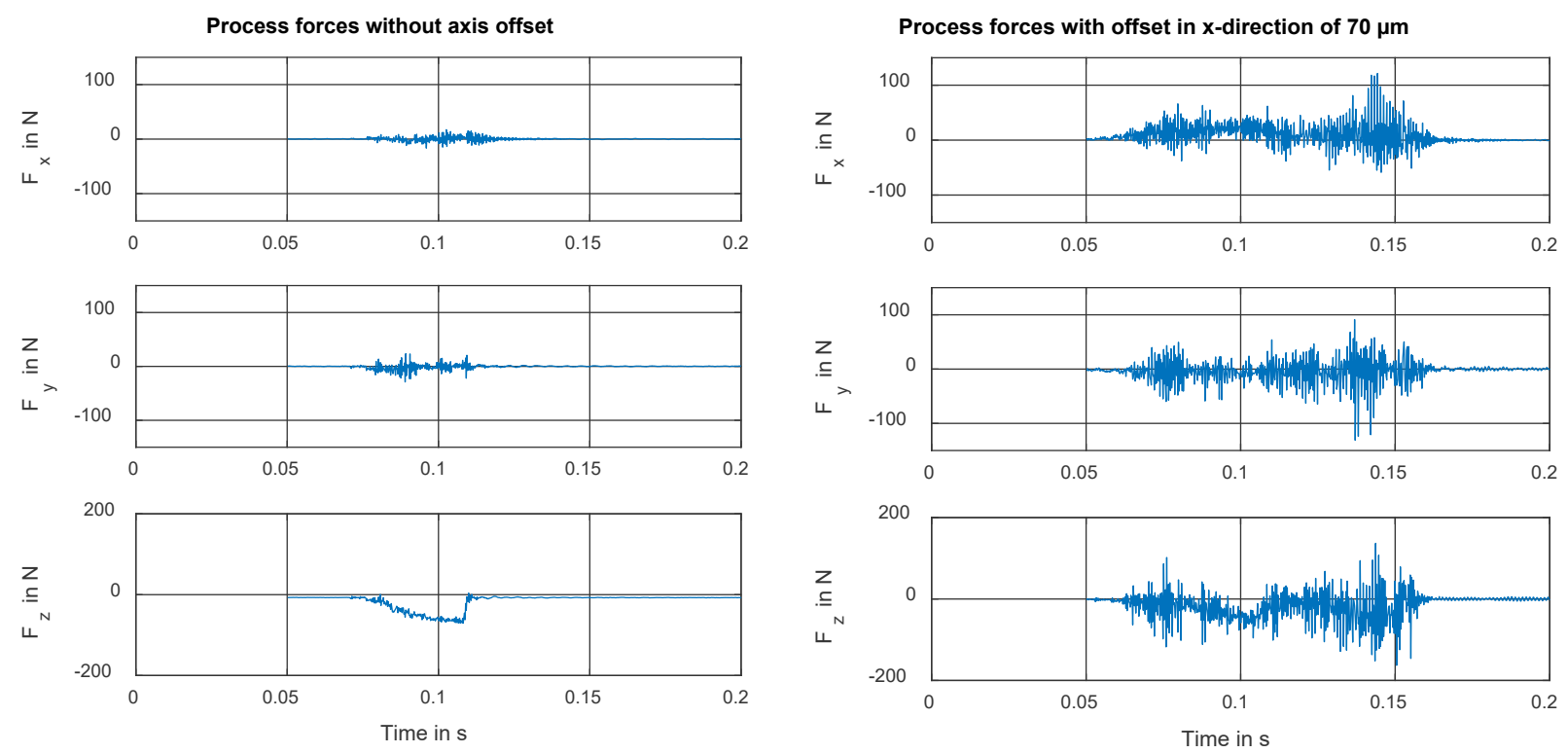

Fig. 4: Forces measured while countersinking without axis offset(left) and with an axis offset of $70 \mu \mathrm{m}$ in $\mathrm{x}$-direction (right)

For the evaluation, the mean values and peak-to-peak values as well as the standard deviation were calculated for each bore for the process forces in the $\mathrm{x}-, \mathrm{y}$ - and $\mathrm{z}$-direction. The mean values show the largest correlations in regard to the axis offsets. For the experiments with unidirectional axis offsets, the correlation coefficients are given in Table 4. The correlation coefficients on the main diagonals, i.e. the couplings axis offset $\mathrm{x}-\mathrm{Fx}$ or axis offset $\mathrm{y}-\mathrm{Fy}$, show a very high 
correlation. The low value of the y-direction for EN-GJL-250 can be explained by the lower number of tests carried out there. Fig. 5 and Fig. 6 show the calculated mean values of the process forces in the $\mathrm{x}$-and $\mathrm{y}$-directions from the individual tests for both materials.

Table 4: Correlation coefficients for unidirectional axis offsets

\begin{tabular}{|l|c|c|c|c|}
\hline & \multicolumn{2}{|c|}{ EN-GJL-250 } & \multicolumn{2}{c|}{ 42CrMo4V } \\
\hline & Mean value $F_{\mathrm{x}}$ & Mean value $F_{\mathrm{y}}$ & Mean value $F_{\mathrm{x}}$ & Mean value $F_{\mathrm{y}}$ \\
\hline Axis offset $\mathrm{x}$ & 0.859 & -0.573 & 0.853 & -0.647 \\
\hline Axis offset $\mathrm{y}$ & 0.568 & 0.554 & 0.447 & 0.727 \\
\hline
\end{tabular}

Countersinking of EN-GJL-250
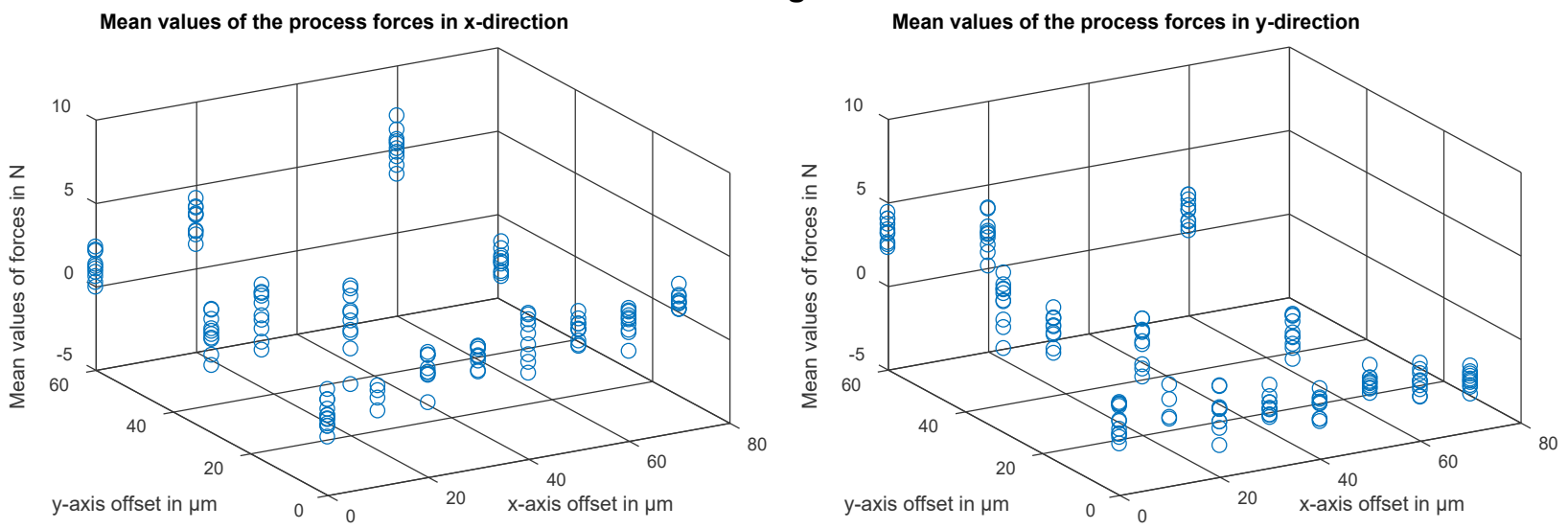

Fig. 5: Countersinking of EN-GJL-250: Mean values of the process forces in x-direction (left) and $\mathrm{y}$-direction (right) as a function of the axis offsets
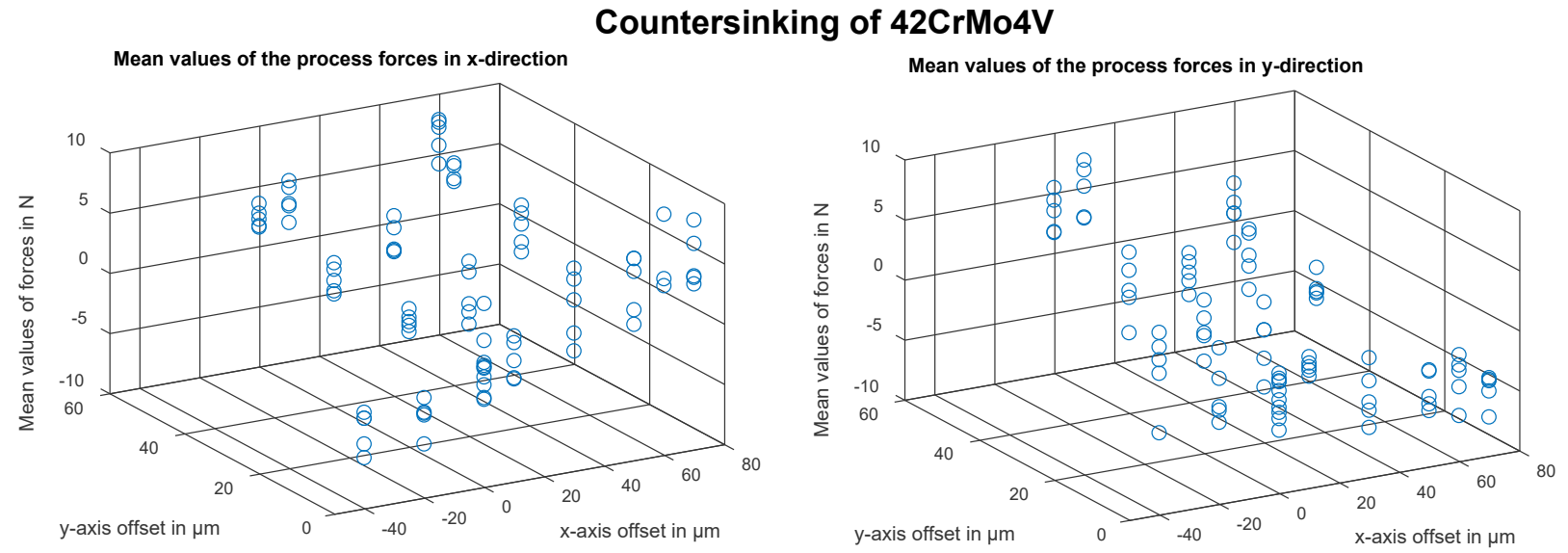

Fig. 6: Countersinking of 42CrMo4V: Mean values of the process forces in $\mathrm{x}$-direction (left) and ydirection (right) as a function of the axis offsets

To predict the axis offsets, the measured data were used to train an artificial neural network (ANN) for each material. The ANN consists of the three layers input layer, hidden layer and output layer (see Fig. 7 left) and is built as feedforward network, so information is only transmitted into one direction without loops or backward connections. The input layer only transfers the input values to the hidden layer and doesn't contain any neurons whereas the hidden and output layer consist of 10 respectively 2 neurons. The structure of a single neuron can be seen in Fig. 7 on the right. Each input $i$ is multiplied with a weight $w$ and added to the bias $b$. The calculated value is then inserted into the transfer function $f$ and gives the output value $o$ :

$$
o=f(w \cdot i+b) .
$$

All output values of one neuron are summed up and provided as inputs for the next layer. For the hidden layer the standard logistic function 


$$
f(x)=\frac{1}{1+e^{-x}}
$$

was used whereas the linear function is used for the output layer [14]. The calculated mean and peak-to-peak values as well as the standard deviations of the process forces in all three directions were used as input data, resulting in 9 total inputs. The outputs are the specified axis offsets in the $\mathrm{x}$ - and $\mathrm{y}$-directions. The neural networks were trained using the Bayesian regularization algorithm [15], using $80 \%$ of the data for training and $10 \%$ for validation and testing each. The regression values achieved were 0.897 for EN-GJL-250 and 0.915 for $42 \mathrm{CrMo} 4 \mathrm{~V}$. Both grids are thus able to accurately determine the axis offset that has occurred by measuring the process forces during countersinking. However, a new network has to be trained for each material.

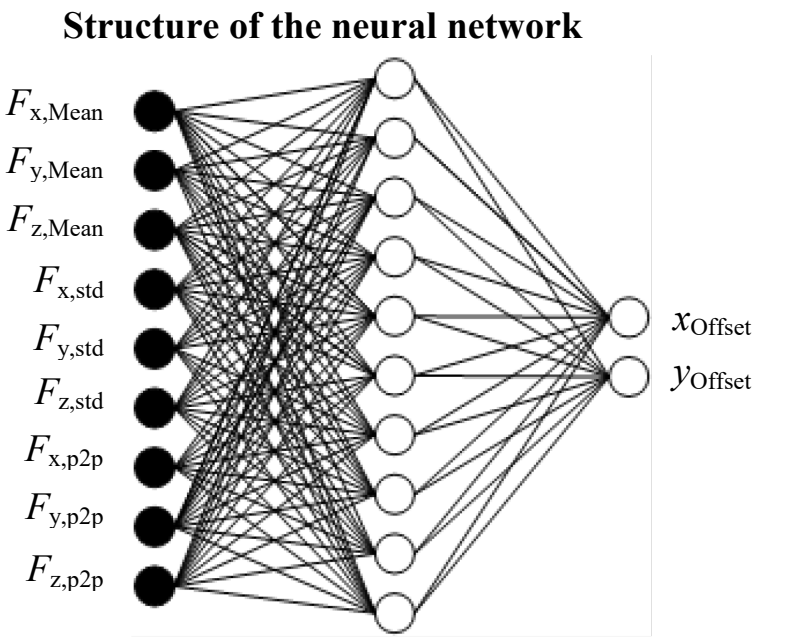

\section{Structure of a single neuron}

Input layer Hidden layer Output layer

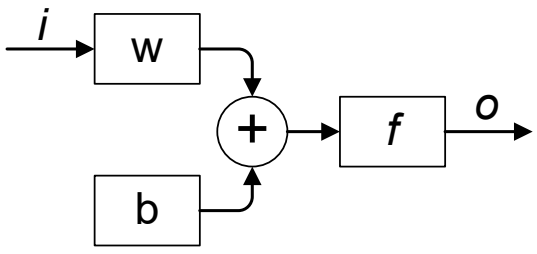

Fig. 7: Structure of the neural network with inputs, hidden layer and outputs (left) and structure of a single neuron (right)

\section{Investigation of the Effect on the Bore Quality}

As already described, the additional countersinking and the subsequent correction of a possibly existing axis offset leads to a short air cut during the subsequent reaming of the bore. Fig. 8 shows the displacement of the reamer along the bore depth from the reference processes with EN-GJL-250 on the left. Each curve shows the deviation of the reamer along one bore. The first deviation was measured in a bore depth of $1 \mathrm{~mm}$, the last one of the reamed area in a bore depth of $40 \mathrm{~mm}$. The radial deflection of the pre-drilled bore was measured in a depth of $43-45.5 \mathrm{~mm}$. The maximum value for the bore deviation is $24.3 \mu \mathrm{m}$, the mean deviation $10.7 \mu \mathrm{m}$. The diagram on the right in Fig. 8 shows the results from the experiments with an axis offset of $60 \mu \mathrm{m}$ both in in $\mathrm{x}-$ and $\mathrm{y}$ direction. The maximum deviation is $28.6 \mu \mathrm{m}$ and the mean value $11.3 \mu \mathrm{m}$. The countersinking process does not lead to a significant deterioration of the bore despite the air cut in the entry phase of the reamer. The proposed method is therefore suitable to compensate for axis misalignments and thus reaming the bores at the desired location. 

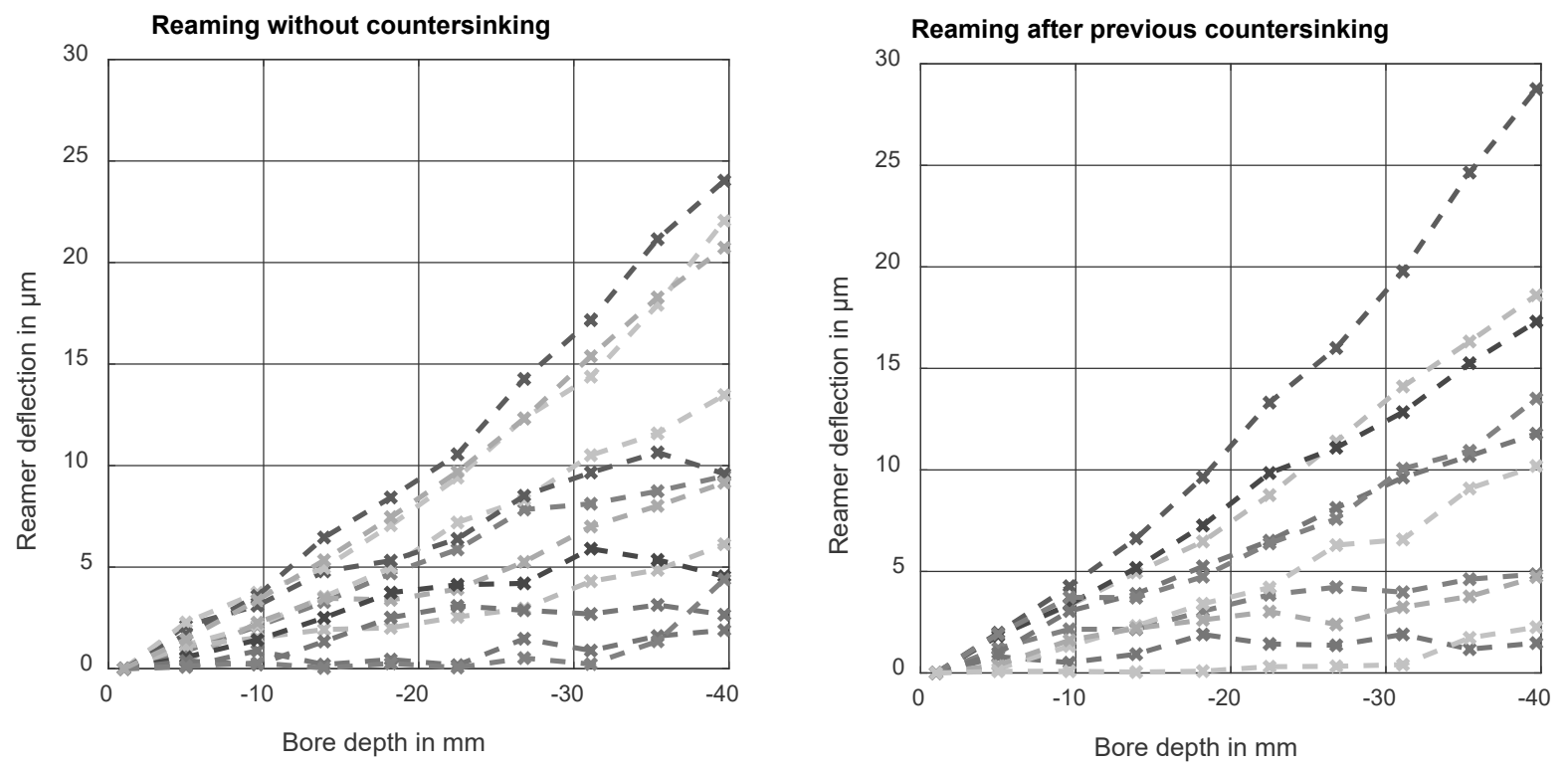

Fig. 8: Deflection of the reamer along the bore. Reaming process without (left) and with previous countersinking and correction of the axis offset (right).

\section{Conclusion and Outlook}

In this paper, an approach for the detection of axis offsets during reaming was presented. Process forces are measured during an additional countersinking process using the reamer with a reduced feedrate before the actual reaming process. The analysis of the process forces by an artificial neural network allows an accurate prediction of the axis offset of the reamer in relation to the pilot hole. This misalignment can then be compensated while the additional countersinking process doesn't increase the deviation of the reamer along the bore depth.

The prediction accuracy of the artificial neural networks can be increased by additional experiments. It could be useful to examine whether data from already existing models of reaming processes can be used for the prediction. However, these cannot calculate the forces during the entry phase of the reamer accurately enough so far.

\section{Acknowledgement}

The authors would like to thank the German Research Foundation (DFG) for funding the research activities at the Collaborative Research Centre "SFB 805 - Control of Uncertainty in LoadCarrying Structures in Mechanical Engineering”.

\section{References}

[1] Koppka, F.: A Contribution to the Maximization of Productivity and Workpiece Quality of the Reaming Process by Analyzing its Static and Dynamic Behavior. Dissertation, Technische Universität Darmstadt. Aachen: Shaker-Verlag 2007

[2] Abele, E.; Haydn, M.; Hauer, T.; Lorenz, U.; Derer, T.: Unsicherheitsoptimierte Prozesskette bei der Bohrungsfeinbearbeitung - Ein Ansatz zur Optimierung der Prozesskette Bohren/Reiben mittels mathematischer Modelle. wt Werkstatttechnik online 101 (2011) H. 11/12, pp. 730 - 736

[3] Pauksch, E.; Holsten, S.; Linß, M.; Tikal, F.: Zerspantechnik - Prozesse, Werkzeuge, Technologien. Wiesbaden: Vieweg + Teubner 2008

[4] Hagedorn, M.; Reinert, K.: Schnittkraftmessung beim Reiben mit Mehrschneidenreibahlen, wt Werkstatttechnik online 95 (2005) H. 6, pp. 485-489. 
[5] Weinert, K. \& Meister, D.: Machining and tool wear, in: Production Engineering, Vol. II (1995) pp. 1-6.

[6] Güth, S.; Bretz, A.; Bölling, C.; Baron, A.; Abele, E.: Control of uncertainty based on machining strategies during reaming, Applied Mechanics and Materials Vol. 807 (2015) pp 162168, (2015) Trans Tech Publications, Switzerland

[7] Yang, J. A.; Jaganathan, V. \& Du, R. (2002), 'A new dynamic model for drilling and reaming processes', International Journal of Machine Tools and Manufacture 42(2), pp. 299 - 311.

[8] Bayly, P. V.; Young, K. A.; Calvert, S. G. \& Halley, J. E. (2001), 'Analysis of Tool Oscillation and Hole Roundness Error in a Quasi-Static Model of Reaming', Journal of Manufacturing Science and Engineering 123, pp. 387-396.

[9] Bhattacharyya, O.; Kapoor, S. G. \& DeVor, R. E. (2006), 'Mechanistic model for the reaming process with emphasis on process faults', International Journal of Machine Tools and Manufacture 46(7-8), pp. 836 - 846.

[10] Bhattacharyya, O.; Jun, M. B.; Kapoor, S. G. \& DeVor, R. E. (2006), 'The effects of process faults and misalignments on the cutting force system and hole quality in reaming', International Journal of Machine Tools and Manufacture 46(12-13), pp. 1281 - 1290.

[11] Mathews, P. \& Shunmugam, M. (1999), 'Neural-network approach for predicting hole quality in reaming ', International Journal of Machine Tools and Manufacture 39(5), pp. 723 - 730.

[12] Abele, E.; Hauer, T. \& Haydn, M. (2011), Modellierung der Prozesskräfte beim Reiben mit Mehrschneidenreibahlen, wt Werkstattstechnik online 101(6), pp. 407-412.

[13] Hauer, T.; Haydn, M. \& Abele, E. (2012), Uncertainties in process chains with focus on the drilling and reaming process, in '1st International Symposium on Uncertainty Quantification and Stochastic Modeling, 26. Februar-02.March 2012, Maresias, São Sebastião, SP, Brasilien, 2012', pp. 569-573.

[14] Hagan, M.; Demuth, H.; Beale, M. \& De Jesús, O.: Neural Network Design, $2^{\text {nd }}$ edition, Boston, 2014

[15] Foresee, F. \& Hagan, M. (1997), 'Gauss-Newton approximation to Bayesian learning', In: The 1997 IEEE International Conference on Neural Networks, pp. 1930 - 1935 